\title{
Exploring the Experiences of Designing and Managing Cooking Online Training During The Covid-19 Pandemic
}

Yong Yit Hiong, Nor Wahiza Abdul Wahat, Diyana Syazana Omar, Hasbul Hadi, Kalaiselvi Karunamurthi, Li Xiaoyan, Mohd Ashrof Husin, Noor Hafida Mohammad Sohami, Nor Ilanah Roslan, Norshahana Mohd Arifin, Qin Yi, Wang Hanwen

To Link this Article: http://dx.doi.org/10.6007/IJARBSS/v10-i12/8330

DOI:10.6007/IJARBSS/v10-i12/8330

Received: 20 October 2020, Revised: 17 November 2020, Accepted: 30 November 2020

Published Online: 15 December 2020

In-Text Citation: (Hiong et al., 2020)

To Cite this Article: Hiong, Y. Y., Wahat, N. W. A., Omar, D. S., Hadi, H., Karunamurthi, K., Xiaoyan, L., Husin, M. A., Sohami, N. H. M., Roslan, N. I., Arifin, N. M., Yi, Q., \& Hanwen, W. (2020). Exploring the Experiences of Designing and Managing Cooking Online Training During The Covid-19 Pandemic. International Journal of Academic Research in Business and Social Sciences, 10(12), 400-415.

Copyright: (c) 2020 The Author(s)

Published by Human Resource Management Academic Research Society (www.hrmars.com) This article is published under the Creative Commons Attribution (CC BY 4.0) license. Anyone may reproduce, distribute, translate and create derivative works of this article (for both commercial and non-commercial purposes), subject to full attribution to the original publication and authors. The full terms of this license may be seen at: http://creativecommons.org/licences/by/4.0/legalcode

Vol. 10, No. 12, 2020, Pg. 400 - 415

Full Terms \& Conditions of access and use can be found at http://hrmars.com/index.php/pages/detail/publication-ethics 


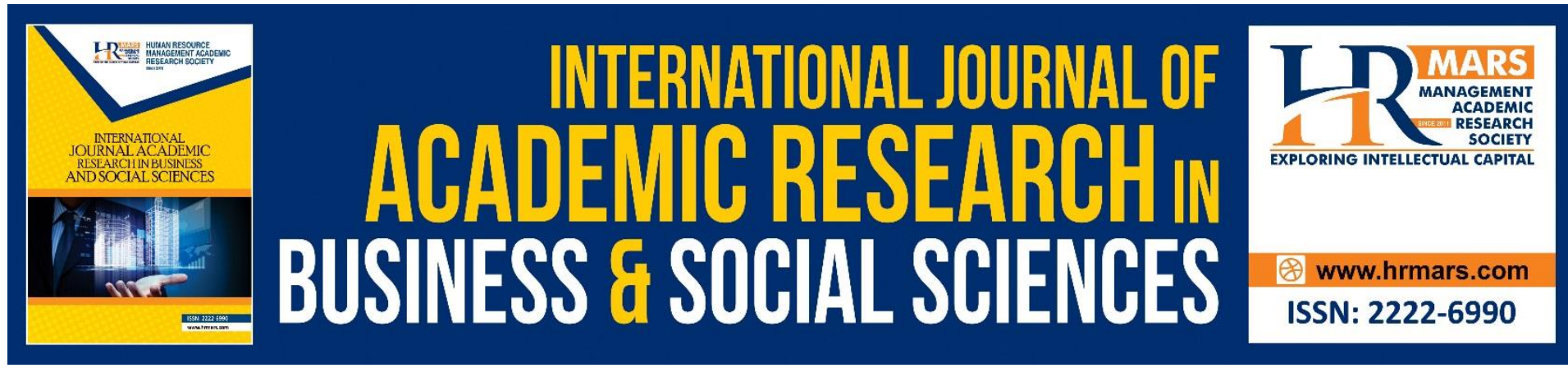

\title{
Exploring the Experiences of Designing and Managing Cooking Online Training During The Covid-19 Pandemic
}

\author{
Yong Yit Hiong ${ }^{1}$, Nor Wahiza Abdul Wahat ${ }^{2}$, Diyana Syazana \\ Omar $^{2}$, Hasbul Hadi², Kalaiselvi Karunamurthi², Li Xiaoyan², \\ Mohd Ashrof Husin², Noor Hafida Mohammad Sohami², Nor \\ Ilanah Roslan², Norshahana Mohd Arifin², Qin Yi², Wang \\ Hanwen ${ }^{2}$
}

${ }^{1}$ Jabatan Perkhidmatan Awam, Bahagian Khidmat Pengurusan, Aras 10, Blok C1, Kompleks C, 62510 Wilayah Persekutuan Putrajaya, Putrajaya, ${ }^{2}$ Faculty of Educational Studies, Universiti

Putra Malaysia, 43400 UPM Serdang, Malaysia

Email:yithiongyong@gmail.com,wahiza@upm.edu.my,GS55614@upm.edu.my, GS55871@upm.edu.my, GS53937@upm.edu.my, GS55652@upm.edu.my, GS56997@upm.edu.my, GS55197@upm.edu.my,GS55178@upm.edu.my, GS56219@upm.edu.my,GS55111@upm.edu.my,GS55789@upm.edu.my

\begin{abstract}
A group of graduate students was assigned to design and conduct training as their group project. Nevertheless, the whole world, including Malaysia was hit by the Covid-19 pandemic. Everyone in the country was under the first phase of the Movement Control Order (MCO). Hence, face-to-face training was not a viable option. Alternatively, the students had to conduct online training. The assignment was the first-time experience for them to design and provide training. A question arose on how well the graduate students' experience was in designing, implementing, and evaluating online training. This article presents a qualitative study on implementing an online training program titled "Learning How to Make Halal Chinese Dumplings Online!" by graduate students in the Training Design and Management course at Universiti Putra Malaysia. This study aimed to explore the design and implementation of the online training program. Data collection was through an online focus group discussion (FGD) involving 11 respondents and a document analysis of a written report by the training implementers. The central theme that emerged from the data analysis is training design for online training. Meanwhile, the sub-themes are as follows: (a) training needs analysis and rationale for online training in making halal Chinese dumplings, (b) training design, (c) training evaluation, and (d) challenges in conducting online training. Methodologically, this study implies the feasibility of successful data collection via online platforms. The findings on the well-designed and implemented online training based on training needs analysis and continuous evaluation suggested that we could still gain access to
\end{abstract}


the ocean of knowledge via formal or informal online learning and education programs at a challenging time of Pandemic Covid-19.

Keywords: Online Training, Training Needs Analysis, Training Design, Training Evaluation, Qualitative Study

\section{Introduction}

The effectiveness of online interventions in developing countries, such as Malaysia, is promising (Zainudin et al., 2018; 2019; Abdrahim, 2020). Past studies on the role of video technology in developing cooking skills among low-skilled domestic cooks through selfdirected learning reported that the video technology could assist the understanding in cooking method, offer reassurance to complete the cooking process, and enhance enjoyment of the cooking process. Participants experience the benefit of having the freedom to view segments of the demonstration they need as often as they want throughout the experiment (Polak et al., 2019).

The current study aimed to explore the graduate students' experiences in designing, managing, and evaluating their online training programs in replacement of the face-to-face training program. Initially they were assigned to design and manage a face-to-face training on any knowledge or skill enhancement based on the results of their training needs analysis (TNA). Nevertheless, due to the Covid-19 outbreak worldwide and the ruling of the Movement Control Order in Malaysia, the face-to-face training program was no longer viable. The situation had led to the design, development, implementation, and evaluation of online training programs by the graduate students. One of the training programs conducted by the graduate students was online training in making halal Chinese dumplings. The title of the online training is "Learning How to Make Halal Chinese Dumplings Online!". The objectives of the online training program were: (a) to teach the participants on how to prepare halal Chinese dumplings in less than two hours, and (b) to enhance the participants' knowledge and skills on important tips in making halal Chinese dumplings.

\section{Literature Review}

Theoretical Foundation

The theory that served as the theoretical foundation for implementing the online training was the integration of action change theory (ACT) and ADDIE Model. ACT is based on the reinforcement learning theory, which emphasizes that complex behaviours are acquired by learning to obtain rewards and avoid punishments (Dickinson \& Balleine, 2002; Rangel, Camerer, \& Montague, 2008; Sutton \& Barto, 1998). Motivated actions resulted from the computation of value. In other words, an individual's brain decides on what actions to take. Also, ACT shares insights from theories of motivation in psychology (Strack \& Deutsch, 2004) and anthropology (Boyer, 2006; Curtis, Danquah, \& Aunger, 2009).

There are different systems in ACT that determine behavior change. They are (a) reward system, (b) goal-directed actions system, (c) habitual actions system, and (d) innate Pavlovian actions system. The systems are described as follows:

a) Reward system - an important target for behavior change interventions. It generates and drives emotions that function as positive or negative rewards in response to desired or undesired stimuli. Zajonc (1980) proposes that affective responses respond faster than cognitive responses. A study by Curtis, Danquah, and Aunger (2009) on 
promoting hygiene behavior in 11 countries found that affiliation, comfort, attraction, disgust, and fear as significant drive for emotion.

b) The goal-directed actions system involves evaluating outcomes, probabilistic estimation of the contingency between the action and the outcome as well as planning incorporate those calculations. Hence, persuasion plays an essential role in planning and driving efforts towards the goal.

c) Habitual actions system - refers to stimulus-response associations learned through repeated practice and rewards in a stable environment.

d) Innate Pavlovian actions system - refers to appropriate responses to specific predetermined stimuli, also known as unconditioned or conditioned responses (Mackintosh, 1983). Innate actions are never reinforced. This innate predetermination offers appropriate default actions in specific environments, which show the advantage not to learn what actions to take. However, innate actions can also lead to maladaptive consequences, such as overeating, addiction, obsessive-compulsive behaviors, and opting for immediate smaller rewards at the expense of delayed larger rewards (Dayan, Niv, Seymour, \& Daw, 2006). Innate actions can also influence habits and goal-directed actions.

One of the mostly referred design models in guiding training designers and developers is ADDIE. ADDIE refers to analysis, design, development, implementation, and evaluation (Aldoobie, 2015). At the stage of analysis, the collection of data is conducted by using interviews, surveys or observation to identify the knowledge, skills or attitudes of learners to achieve training objectives effectively. At the design stage, the designer creates a blueprint on how to deliver the training. At the development stage, the designer integrates technology with learning materials that will be used during the training. At the implementation stage, the blueprint is translated into actions. The implementation phase represents transforming the entire training and planning into action. This phase includes the preparation of training instructors, learners, and the learning environment.

The final stage is evaluation. It is first and foremost important to understand the difference between measurement and evaluation. Measurement refers to obtaining information, which results from a comparison based on a given standard. Meanwhile, evaluation refers to the judgement based on the information provided by measurement. It is usually about the value, which an individual attaches to any object, subject or experience. In short, training evaluation refers to the training value determined by each important stakeholder; trainees, trainers, training designers, training management, and/or training vendors (Nickols, 2005).

\section{Training Needs Analysis and Training Objectives}

Training needs analysis (TNA) is an essential component of a training program and it takes place at the very initial stage of training (Abdrahim, 2020; Goh et al. 2020; Abdul Wahat, 2018). In other words, it occurs at the planning stage of a training. TNA is a method of determining the appropriateness and significance of training programs by investigating gaps in knowledge, competency, and skills of potential participants. The results of training needs analysis will serve as a guidance on the design and direction of effective training programs to anticipate future needs and change of individuals and/or organizations (Purnell, 2020; Ludwikowska, 2019). Hence, it helps to form training objectives, scope, and content based on the obtained evidence related to the needs and desired changes of potential participants of 
the training. Besides that, the result of TNA can also guide training designers to select the most suitable teaching and learning methods for training programs (Bae \& Roh, 2019).

According to Barbazette (2006), training needs analyses are usually conducted through the administrations of a face-to-face or online surveys composed of close-ended and open-ended questions, interviews with subject matter experts, document analysis, focus group discussions, and direct observation (Salas \& Stagl, 2009; Rothwell \& Kazanas, 2011) to obtain answers for the following important questions: (1) Why is the gap or problem occurring?, (2) Who is affected?, (3) How to reduce the occurring gap?, (4) What is the expected level of performance?, and (5) When is the best time to conduct the training? The training designers could achieve the answers with clear TNA objectives, appropriate stakeholders, data collection methods, specifications for instruments and protocols, data analysis methods, and decisions upon gathering the data.

\section{Training Design and Evaluation}

The process of designing any online training program is based on learner-centered psychological principles. Such is because online training is featured with self-pace, selfdirected, and self-motivated elements. Hence, the design of an online training program should be susceptible to: (a) Metacognitive and cognitive factors, (b) affective factors, (c) developmental factors, (d) personal and social factors, and (e) individual differences (Reigeluth, Beatty, \& Myers, 2017). Metacognitive and cognitive aspects refer to the nature, goals, and construction of the learning process, filtered through the learner's perception, thoughts, and feelings, which finally lead to a meaningful learning experience. Affective factors refer to intrinsic motivational influences to learn, including self-awareness, goals, personal expectations, and interests. Developmental factors refer to development constraints and opportunities in physical, social, emotional, or intellectual aspects. Personal and social factors refer to facilitated learning by social interaction and communication with others in an appreciation of potentials and talents, which may build social acceptance and self-esteem. Finally, individual differences refer to differences which resulted from environmental functions, heredity or personal filters, such as personal belief, thought, and experience shaped by past learning and experiences.

Since 1975, the literature and practices of training evaluation have been far dominated by the Kirkpatrick model (TKM), focusing on the four levels of evaluation; reactions (smiley sheets), learning (acquired competencies and skills), behavior (the extent to which participants can apply what they have acquired from the training), and results (the extent to which expected outcomes are produced from the training and exhibit the training eligibility) (Kirkpatrick, 1975a; 1975b). Typically, in practice, most training stakeholders are more inclined towards reaction evaluation. Trainees would be interested in the applicability and relevance of the training content that appeals to their needs. They would also be interested to participate when the training is perceived as not wasting their time (Nickols, 2005). Training vendors want to know if their clients are happy with their training product (Nickols, 2005).

By late 1990s, critiques on TKM led to the fifth level of training evaluation, which suggested the assessment of training effectiveness on external stakeholders, such as financial return of investment (ROI) for organization and society (Phillips, 1997; Kaufman \& Keller, 1994; Watkins, Leigh, Watkins \& Kaufman c, 2002). Psychometrically, a sound evaluation is vital in examining the reliability of a professional training. Even though evaluation is listed last in the 
ADDIE model, an evaluation must be conducted at every stage in the training blueprint to make sure that the learning program meets the learning objectives. At the evaluation stage, the training is being assessed beginning from the need analysis, development and implementation stages (Abdrahim, 2020; Goh et al. 2020; Abdul Wahat, 2018). The results and impacts of the training are being evaluated as well. A training evaluation should also focus on the training content. As training evaluations tend to be both time-consuming and labour intensive, there is an increasing demand for the online training evaluation in various contexts, including those related to food safety preparation (Kirkpatrick, 1959; Grohmann \& Kauffeld, 2013; Gillis, 2000). A study by Howton et al. (2016) employed an online training evaluation focusing on four categories: (1) Content and outcomes, (2) assessment and transfer, (3) technology design and requirements, and (4) operations and support.

\section{Values and Challenges of Online Training Programs}

Online training programs through mobiles, tablets, laptops, and desktops have identified the values and benefits compared to the traditional face-to-face training mode. Even though most of the time, there would be limited interactions between trainers and the participants, online training programs provide the feature of flexibility. It reduces time commitment on the part of the participants in the sense that they could attend the online training at their own time, pace, and space. They are free from the travelling issue and saved from the problems of having their time and focus taken away from their job commitment. As it involves the element of self-pace and self-directed learning, the online training content can also be revisited. Thus, it may contribute to a better content understanding and consolidation (Gayed et al., 2018). Schmeeckle (2003) who conducted an empirical investigation, compared online and classroom training and reported that the effectiveness of an online training is similar to the effectiveness of a classroom training. There is no significant difference in learning between the two modes of training. In the study, efficiently, the online training was completed in a shorter duration of time and involved less cost. Another study was conducted by Polak et al. (2019) on the feasibility and educational value perceived by health professionals towards an online cooking module. Polak et al. (2019) reported that $70 \%$ of the respondents rated the online cooking program as either good or excellent. This result is due to the receipt of items preparation before the session, and real-time visual learning opportunity as well as experiences.

Nevertheless, unlike the face-to-face training programs, the participants are in a remote distance from the trainer as well as the training implementer for online training programs. Hence, online training may confront challenges, such as less engagement, curiosity, focus, immersion as well as less seriousness in learning among the participants (Hara \& Kling, 2001).

There are opportunities for participants who did not complete the training program to fill up the evaluation form. They also have the opportunity to evaluate the training program either before or after two months after the training. Therefore, such a variety may lead to biases in the evaluation results (Gayed, Tan, LaMontagne, Milner, Deady, Milligan-Saville \& Glozier, 2019).

\section{Methodology}

This qualitative study was carried out using two methods of data collection. Firstly, a focus group discussion (FGD) was conducted to collect data from training designers and 
implementers of the online training program in making halal Chinese dumplings. The focus group is a useful method for a qualitative research when the goal of the research is to evaluate people's understanding and experiences about a given topic or situation and in assessing and identifying training needs (Kitzinger, 1995; Robinson, 1999). Secondly, a document analysis was conducted by referring to a report provided by the online training implementers who were also the participants of the FGD. Document analysis refers to a systematic procedure to evaluate documents in various forms, including printed and electronic materials. The researcher would examine and interpret the data from the document(s) without any element of biasness to obtain and understand the meaning and then develop empirical knowledge from the data (Corbin \& Strauss, 2008; Rapley, 2018).

\section{Participants and Sampling}

The focus group discussion (FGD) was conducted with eleven designers and implementers of the online training in making halal Chinese dumplings. The demographic backgrounds of the designers and implementers of the online training is presented in Table 1 . The purposive sampling was adopted in selecting the respondents of the focus group discussion. Purposive sampling is a non-probability sampling technique to choose a sample of subjects. The samples are usually those who have the characteristics of interest and the most information to achieve the objectives of the study. This sampling technique is most suitable if the researcher does not aim to generalize the results of the study. It is also known as judgemental, selective or subjective sampling (Crossman, 2017; Etikan et al., 2016). In relation to this study, the researcher did not intend to generalize the results of the design and implementation of the online training in making halal Chinese dumplings.

The criteria of the selected respondents were: a) Graduate students of the Training Design and Management course under the Masters in Human Resource Development (M.HRD) program at Universiti Putra Malaysia, and b) involved in either designing or implementing the online training program in making halal Chinese dumplings. Hence, there was an element of homogeneous composition in the focus group discussion. All of them were contacted and later recruited after they voluntarily provided their consent to participate in the study.

Table 1

Demographic Characteristics of Focus Group Discussion Respondents

\begin{tabular}{llll}
\hline Nickname & Age & Gender & Education \\
\hline Y & & & \\
X & 34 & Female & Masters in Human Resource Development \\
$\mathrm{AL}$ & 24 & Female & Masters in Human Resource Development \\
$\mathrm{I}$ & 36 & Female & Masters in Human Resource Development \\
$\mathrm{K}$ & 26 & Male & Masters in Human Resource Development \\
$\mathrm{A}$ & 38 & Female & Masters in Human Resource Development \\
$\mathrm{W}$ & 24 & Female & Masters in Human Resource Development \\
$\mathrm{H}$ & 37 & Male & Masters in Human Resource Development \\
$\mathrm{D}$ & 34 & Male & Masters in Human Resource Development \\
$\mathrm{N}$ & 35 & Female & Masters in Human Resource Development \\
$\mathrm{Q}$ & 24 & Female & Masters in Human Resource Development \\
& 26 & Female & Masters in Human Resource Development
\end{tabular}




\section{Procedure}

The FGD was facilitated by a researcher who is a subject matter expert in training design and management. Since the study was conducted during the Movement Control Order (MCO) in Malaysia, the focus group discussion was conducted online via Zoom. Zoom is an online platform for video conferencing. The virtual approach used in conducting the study itself signifies an alternative approach in conducting a focus group discussion in the era of IR 4.0 and the Internet of things (lot). Its effectiveness is not questionable. Online focus group discussion highlights the element of dynamism, modernity, and competitiveness that online focus groups boast an aura of dynamism, modernity, and competitiveness that surpasses classic problems with a face-to-face focus group discussion (Edmunds, 1999).

The involvement of eleven respondents was the appropriate number of respondents as previous studies have reported 3-21 respondents with a median of 10 respondents (Nyumba, et.al., 2018). Instead of in-depth interviews, the focus group discussion was selected as the most suitable data collection technique because the group dynamics and synergistic relationships among the respondents would contribute to a rich data generation (Kitzinger, 1994; Thomas, MacMillan, McColl, Hale, \& Bond, 1995). The FGD was conducted in English and it lasted for 90 minutes. The participants were informed that the FGD would be videotaped via the Zoom application. As mentioned earlier, their prior consents were obtained. The facilitator began with a briefing on the aim of the FGD, followed by an icebreaking session. The FGD was guided by an FGD protocol in the form of semi-structured questions, as illustrated in Table 2. Further probes were also used to obtain additional information.

Table 2

Focus Group Discussion Protocol

\section{Main Questions}

1. How did you conduct the training needs analysis (TNA)?

2. What was your experience in designing the making of halal Chinese dumplings online training?

3. How was evaluation conducted for your halal Chinese dumplings online training?

4. Were there any challenges in conducting the making of halal Chinese dumplings online training?

At the second phase of this study, the findings from the FGD were triangulated via a document analysis on a written report regarding the online training. Triangulation refers to the application and combination of several research methods in the study of the same phenomenon. It was conducted to validate and increase the credibility of the findings of this study (Bogdan \& Biklen, 2006). The researcher appraised the content of the whole report to synthesize the data in the report. The synthesis process led to the generation of a major theme and sub-themes of the online training program. The findings from the document analysis serve as the empirical support to the identified major theme and sub-themes from the FGD.

The document analysis, which was performed on the report prepared by the training designers and implementers of the online training included contents on the training needs analysis (TNA), which involved 39 respondents. The data on demographic profiles, knowledge on dumplings, interest in dumpling making, and intention to participate in halal Chinese 
dumplings making online training was collected via a Google Forms. The majority of the respondents who answered the TNA questionnaires were female (74.4\%). Only ten were male respondents ( $25.6 \%$ ). The respondents' average age was 39 years old, belonging to the category of middle age adult.

\section{Results and Discussion}

The focus group discussion (FGD) involved 11 respondents ( 5 females and 6 males) who were designers and implementers of the online training program.

The central theme that emerged from the data analysis is training design of online training and the sub-themes are as follows: (a) Training needs analysis and rationale for online training in making halal Chinese dumplings, (b) Training design, (c) Training evaluation, and (d) Challenges in conducting online training.

Training Needs Analysis and Rationale for Online Training in Making Halal Chinese

\section{Dumplings}

Prior to the implementation of the online cooking training, the training designers conducted an online survey via a google form to find out whether or not the public would be interested in learning how to make halal Chinese dumplings and what type of dumpling preparation they would prefer:

According to Miss $\mathrm{Y}$, one of the online training designers:

"Since the outbreak of Covid-19, there has been a growing awareness of taking charge of personal health and well-being. Hence, our group strongly believe that participants would be highly motivated and enthusiastic in learning about healthy life through our training program tailored for them. To validate our belief and assumption, we conducted an online survey using Google Forms as well as referred to some literature as the secondary data to identify the easiest and most suitable healthy food preparation for our online training. From our readings, we found that in the Spring Festival in China, people eat dumplings to express the relationship between themselves and God. Dumplings can be handmade at home. It provides the opportunity for chatting among family members, especially with the children during the process of making dumplings. Since everyone has to stay at home for a very long time during the $\mathrm{MCO}$, we thought that teaching people how to make halal and easy dumplings would be a great idea for our online training". They also wanted to learn dumpling making as one of the bonding activities with their families during the Movement Control Order (MCO)."

During the training needs analysis (TNA), they discovered the potential participants' tendency to learn how to make dumplings, favorite dumpling fillings, dumpling cooking style, and preferred online duration. All this information facilitated them to design the online dumplingmaking training according to their potential participants' needs. Another respondent, who was also involved in the online training design, added:

"For the training needs analysis, the result from our online survey via the Google Forms shows that the majority of our respondents have eaten dumplings with chicken, shrimp, and vegetable fillings as their favorite fillings. They acknowledged dumpling as healthy food, and they prefer steamed and fried dumplings rather than boiled dumplings. However, most of the respondents have never made dumplings and would love to learn how to make dumplings known as a luxurious food at a minimal cost.

The survey data also told us that potential participants prefer online training that is not more than 10 minutes. So, all these data collected during the training needs 
analysis guided us on the significance of conducting an online demonstration in preparing dumplings. The data also helped us in building the content for online training".

The above findings are synchronous to the document analysis results performed on the report prepared by the training designers. It was written in the report that although most of the respondents $(87.2 \%)$ do not know how to prepare dumplings, $92.3 \%$ (36 respondents) expressed their interest in learning how to make dumplings, which is known as luxurious food, at a minimal cost. A similar percentage was reported in terms of high likelihood to learn the dumpling making as one of the bonding activities with their families during the Movement Control Order (MCO).

The findings of this study are very much parallel to prior studies which have reported on the importance of TNA to determine the appropriateness and relevance of training programs by examining the gaps in the interest, knowledge, skills, and competencies of potential participants (Purnell, 2020; Ludwikowska, 2019; Abdrahim, 2020; Goh et al. 2020; Abdul Wahat, 2018). Similar to face-to-face or conventional training, the need to conduct TNA is very much relevant to ensure the effectiveness of online training. The findings of this study exhibited that outcome of the review of the training needs have guided the design and direction in implementing the online training. The understanding on the interests, needs, knowledge and skills gaps of the potential participants obtained from the TNA has led the online training designers and implementers to decide important components on the training content, which is inclusive of (a) brief introduction on the history and background of the dumplings, and (b) demonstration of a short, simple, and attractive process of dumpling making. The results of the TNA have also guided them to select Whatsapp, Youtube, Facebook, and emails as the most suitable social media channels for the purpose of information dissemination and marketing. The analysis on the training report found that the viewers discovered the opportunity to participate in their online training program through WhatsApp (39.2\%), Instagram (11.9\%), Facebook (6.8\%), and other online platforms, such as Google and YouTube (4.0\%).

The decision to use social media as the marketing platform and the successful outcome of using it for the online training provided support to previous studies on powerful effect of social media as a viral marketing tool, despite less effort needed to reach out to potential participants or clients (Fouad, 2017, Subramani \& Rajagopalan, 2003).

\section{Training Design and Implementation}

In terms of designing the online training program, the training designers proceeded based on the training needs analysis (TNA) results to build the materials and content for the training. As highlighted by Reigeluth, Beatty and Myers (2017), the training designers have to focus on affective factors inclusive of the potential participants' interests and personal expectations if they were to engage in the halal Chinese dumpling making online training.

According to one of the training designers during the focus group discussion:

"We prepared the cooking materials and ingredients for a video demonstration recording. Then, the materials were edited to include a subtitle for the video and a trial run. Upon completion, we sought for our lecturer's approval before disseminating it online. We promoted our online training posters using social media, such as WhatsApp groups, YouTube, and Facebook. The halal Chinese dumpling making demonstration video was then uploaded on YouTube". 
Accordingly, the document analysis that was conducted on the training report found that in terms of preferences, the respondents' all-time favourite fillings are chicken (100\%), shrimp (94.9\%), vegetables (89.7\%), beef (82.1\%), and lastly dried shrimp (51.3\%). The majority of them preferred to watch an online video demonstration of dumpling making for less than 10 minutes, which behaviour aligns with the science of attention (Benjamin, 2002). The majority of the respondents ( $94.9 \%$ ) agreed to receive the online video demonstration link via email and social media. In terms of the overall implementation of the online training, the designers explained the whole process as illustrated in Figure 1.

Figure 1 explains how the process began with a training needs analysis (TNA) via Google Forms, to assess the necessity of the online training. The results of the TNA, which indicated the need for the online training had led to the setting up of the committee for task assignments. The structured committees were promotion, video and linguistic, research as well as analysis and editor. The promotion committee was in charge of making the advertisement materials, such as online posters and marketing the online training through various social media channels. The video and linguistic committee was in charge of developing the dumpling making video. The research committee was in charge of researching on the dumpling making background and history as well as other related literature review on training design and management. The analysis and editor committee were in charge of training needs analysis (TNA), evaluation, and report editing.

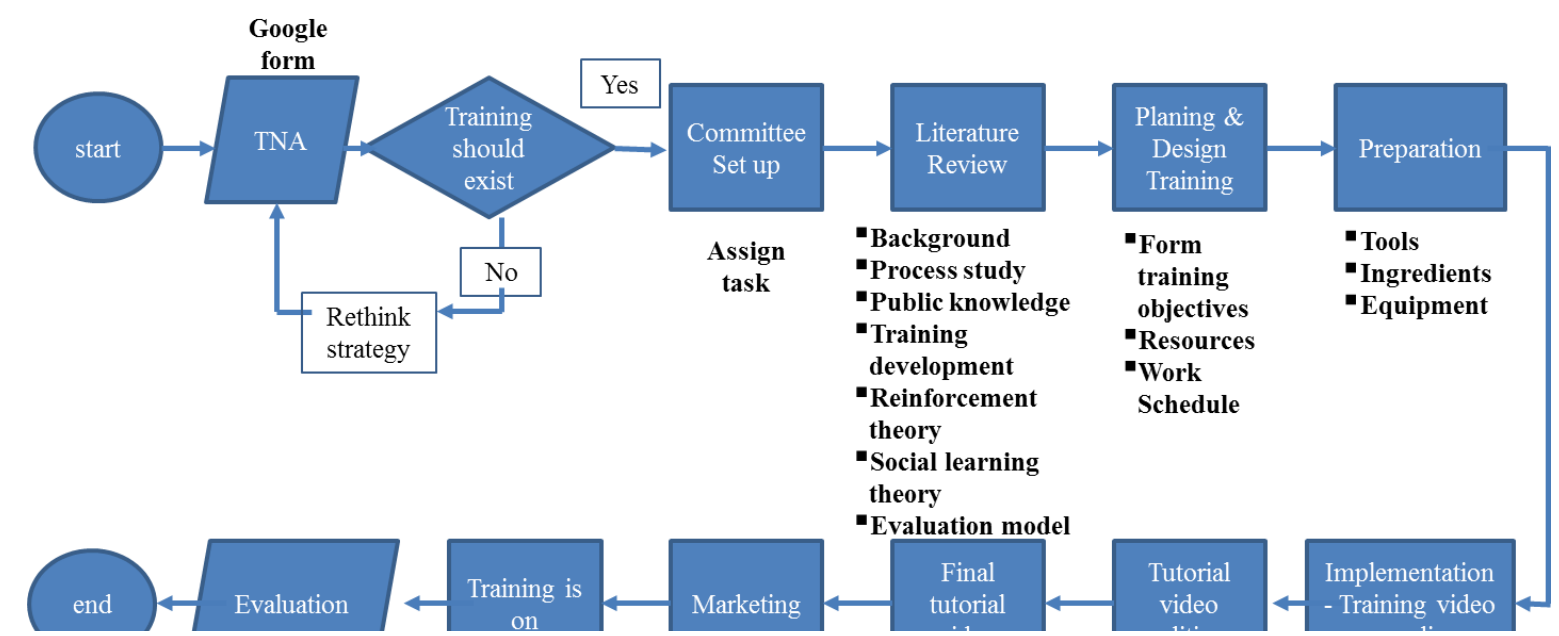

Figure 1. The Implementation of Learning How to Make Halal Chinese Dumplings Online Training
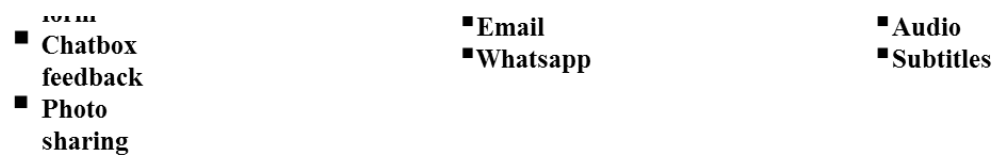

The research and review of literature were conducted by the training designers before they embarked on the planning and design of the online training. After gathering sufficient information from the TNA results and literature, they formed the objectives, prepared necessary resources (tools, dumpling ingredients, and equipment), and charted the work schedule for the online training. Next, they video recorded the halal Chinese dumpling making session and edited it into a tutorial video featured with subtitles and audio. Upon the finalization of the video, the marketing was initiated to potential participants via various social media. The video was uploaded on YouTube, which allows a public access to the potential participants to join the online training with an embedded link of the evaluation form. The above narration is very much in line with the proposition of the ADDIE model (Aldoobie, 
2015). The collection of data is very important to ensure the necessity of the training itself. Accurate objectives of the training and every decision made in the process of designing the halal Chinese dumpling making online training were also based on the collected data at the phase of TNA. Finally, the evaluation, which occurred at the earliest stage in the form of TNA was completed as a final evaluation on the results and learning transfer of the online training. Training Evaluation

Past studies have identified participants' characteristics as success factors for online training or distance learning (Amoozegar, et.al., 2017; Zainudin et al., 2018; 2019; Abdrahim, 2020). In this study, the respondents claimed to have achieved their online training objectives. In other words, they perceived the online training as successful (Nakayama, et.al., 2014). The documented report on the participation of the online training shows that 124 participants had joined the halal Chinese dumpling making online video demonstration, of which 94 (75.8 $\%)$ of them were female participants. Most of the participants were from the Malay ethnicity (83.1\%), followed by Chinese ethnicity (8.1\%), Indian ethnicity (7.3\%), and lastly other races (1.6\%). Among the 124 participants, the highest education level was bachelor's degree (62.1 $\%)$, followed by master's degree (12.9\%), diploma (10.5\%), and Malaysian Certificate of Education or SPM (8.1\%). Among the participants, $41.9 \%$ of them were students, $33.1 \%$ were employees of the public sector, and $20.2 \%$ were employees from the private sector. The majority of them were Malaysians (97.6\%), and the rest were from China, Nigeria, and Mauritania $(0.8 \%)$. Hence, it could be deducted from the evaluated data that most of the respondents were mostly young Malay female who would be interested to learn new cooking skills via social media platform and perceived such online training as useful to them. The results also supported previous study by Sedek et al., (2012) that stated technology-based program is favourable among undergraduates in Malaysia.

According to one of the respondents, Mr.H:

"In terms of the training success, our participants have learnt how to cook dumplings in less than 2 hours. They were able to cook dumplings at their convenience and made the experience as part of good memories with the family during the MCO. Overall, our participants were satisfied with the online training dumpling video and they would recommend it to others".

The document analysis results empirically support the above claim. The written report on the online training show that half of the participants responded that they would start making dumplings in a week after they watched the online video demonstration. Subsequently, 27.4 $\%$ responded via Google Forms that they would start making dumplings straight away. Meanwhile, $12.9 \%$ responded that they would like to try making dumplings within a few hours after watching the online video demonstration. The majority of the participants $(95.2$ $\%)$ agreed that making dumplings is a warm and pleasant family activity.

The report's evaluation analysis also found that the majority of the participants (96.8 \%) agreed that the video displays the full process on how to make dumplings. The majority of the participants $(96.0 \%$ ) also agreed that every shoot of the video demonstrates the dumpling making step by step. Similarly, most participants $(96.8 \%)$ agreed that the chef portrayed professionalism in making dumplings. Equally, most participants (96.8 \%) agreed that they learned how to make dumplings by themselves through the online video demonstration. In terms of interest in Chinese food, most participants (92.7 \%) responded that they were 
interested in Chinese food after watching the online video demonstration. As for sharing back on dumpling making, the majority of the participants (83.1\%) indicated that they would share their handmade dumplings in the social media through the chatbox/comment box to provide feedback.

Interestingly, some participants even shared the pictures of their homemade dumplings within a week or two weeks after they participated in the online training. These impactful results indicate the feasibility of online cooking training in enhancing the participants' knowledge and skills. Thus, this study adds up to the recent literature on the need and demand for online training in challenging times of Pandemic Covid19 when dealing with the issue of accessibility to training location and logistics (Abdul Wahat \& Hamid, 2018; Zainudin et al., 2018; 2019; Abdrahim, 2020).

\section{Challenges in Conducting Online Training}

The online training designers have also shared the challenges, which they encountered in implementing the online training during the phase of Movement Control Order (MCO). At the preparation stage, they faced a difficulty in gaining access to the required tools to develop the necessary materials and features for the online training. They also faced a difficulty in getting the ingredients to make dumplings for the training.

According to one of the training implementers, Mr.A:

"Due to the MCO, we lacked proper tools and ingredients. In terms of training content, we could only demonstrate on boiled dumplings in the online video and could not show more cooking methods, like fried dumplings, steamed dumplings, and so on".

Due to the inconsistency of the Internet connection, the training designers and implementers at times faced barriers in having a smooth discussion before conducting the online training. In addition, they also could not engage with the participants as much as they expected to. Such experience is very much relevant to the literature, which has highlighted that less engagement and focus as part of the challenges in conducting an online training (Hara \& Kling, 2001). This situation is indicated in the following shared statement by Miss I:

"An inconsistent Internet connection also had led to several communication barriers. We faced difficulties to engage in real-time online communication. At the phase of training implementation, we were also worried that not all of our participants would have a strong Internet connection to watch the full video",

The above findings are further supported by the training designers' and implementers' observation on the YouTube analysis on audience retention. Audience retention refers to measuring how much people watch the video embedded in the online training. The shape of the audience retention graph indicates, which part of the video was watched the most, and which part of the online video was least attractive to the viewers. The document analysis suggested that the audience retention curve shows the number of views for every moment of the video as a percentage of the total number of video views. The estimated average minutes watched per view for the video is $1: 44$ minutes or $25 \%$.

\section{Conclusion}

Training designers and providers need to face and be ready to make difficult decisions in converting many of their face-to-face training into online training considering the increasing number of Covid 19 positive cases in Malaysia and all around the world. The requirement of social distancing, and to some extent, to stay at home or be under quarantine, due to certain pandemic circumstances, reflects the need for training designers and providers to be more 
adaptive and creative to ensure that their training quality and standards are not compromised.

However, there is no best practice from any of the models for us to replicate one hundred percent, especially in online training cases, although there are various models of training design. It depends on the context of where online training is conducted, the preferences, characteristics, and available resources surrounding the participants. An issue as simple as the speed of Internet connection can create difficulty for implementing online training. Thus, each online training would be crafted based on the needs identified from the potential participants' training needs analysis (TNA). The TNA results serve as an essential guideline in designing, providing, and evaluating the effectiveness of the online training.

\section{Implication}

Methodologically, this study implies the feasibility of successful data collection via online platforms. In other words, empirical studies for social sciences could still be conducted during the challenging times of Covid-19 pandemic. The findings of this study also imply that a welldesigned online training program would benefit and fulfill the needs of learners. We could still gain access to the ocean of knowledge via formal or informal online learning and education programs.

The COVID-19 pandemic brought worldwide dramatic changes to training methods. Many providers of training have moved to providing their training courses and programs using fully electronic online modes. In emergency situations, online training and e-learning experiences not only raise challenges, but also offer opportunities. The need for an online training during COVID-19 pandemic for the enhancement of knowledge, skills, and affective domains of individuals highlights the demand for training designers and providers to continuously study and improve the process of having the best approach to ensure effectiveness in providing their services.

Due to the social distancing measure to discourage group transmission of the virus, it is a hightime for training designers and providers to shift their paradigm and approaches from the conventional styles of training. In the current situation, the training needs analysis (TNA) essentially serves as a vital element to identify the participants' needs and the training objectives. The TNA also helps identify the best tools, materials, and design to ensure the participants' learning outcomes and expectations were achieved. Despite the new challenges that training designers and providers face in offering online-based training with various features, it is an opportunity for them to reach out to a broader target market as it is borderless and impose a lesser cost to potentially interested participants.

\section{References}

Abdul Wahat, N. W., \& Hamid, T. R. A. (2018). Motivational Virtual Training for People with Disabilities in Rural Areas of Malaysia. Pertanika Journal of Social Sciences \& Humanities.

Aldoobie, N. (2015). Technology integration and learning theory. American International Journal of Contemporary Research, 5(6), 114-118.

Amoozegar, A., Daud, S. M., Mahmud, R., \& Jalil, H. A. (2017). Exploring learner to institutional factors and learner characteristics as a success factor in distance learning. International Journal of Innovation and Research in Educational Sciences, 4(6), 647-656. 
Bae, K. S., \& Roh, Y. S. (2020). Training needs analysis of Korean nurses' neurological assessment competency. Nursing \& Health Sciences, 22(1), 107.https://onlinelibrary.wiley.com/doi/full/10.1111/nhs.12654

Barbazette, J. (2006). Training needs assessment: Methods, tools, and techniques. John Wiley \& Sons.

Bogdan, R. C., \& Biklen, S. K. (2006). Qualitative research in (validation) and qualitative (inquiry) studies. It is a method-appropriate education: An introduction to theory and methods. Allyn and Bacon.

Boyer, T. W. (2006). The development of risk-taking: A multi-perspective review. Developmental Review, 26(3), 291-345.

Corbin, J., \& Strauss, A. (2008). Strategies for qualitative data analysis. Basics of qualitative research. Techniques and procedures for developing grounded theory ( $3^{\text {rd }}$ ed). Thousand Oaks.

Curtis, V. A., Danquah, L. O., \& Aunger, R. V. (2009). Planned, motivated and habitual hygiene behaviour: an eleven country review. Health Education Research, 24(4), 655-673.

Dayan, P., Niv, Y., Seymour, B., \& Daw, N. D. (2006). The misbehavior of value and the discipline of the will. Neural Networks, 19(8), 1153-1160.

Dickinson, A., \& Balleine, B. (2002). The role of learning in the operation of motivational systems. Stevens' handbook of experimental psychology. https://onlinelibrary.wiley.com/doi/full/10.1002/0471214426.pas0312.

Gayed, A., Tan, L., LaMontagne, A. D., Milner, A., Deady, M., Milligan-Saville, J. S. \& Glozier, N. (2019). A comparison of face-to-face and online training in improving managers' confidence to support the mental health of workers. Internet Interventions, 18, 100258.

Hara, N., \& Kling, R. (2001). Student distress in web-based distance education. Educause Quarterly, 24(3), 68-69.

Kaufman, R., \& Keller, J. M. (1994). Levels of evaluation: Beyond Kirkpatrick. Human Resource Development Quarterly, 5(4), 37180.https://onlinelibrary.wiley.com/doi/abs/10.1002/hrdq.3920050408

Kirpatrick, D., \& Kirkpatrick, J. D. (1975). Evaluating training programs. Ta McGraw-Hill Education, Madison, Wis. ASTD.

Kirkpatrick, D. L. (1975). Techniques for evaluating training programs, Evaluating Training Programs. Alexandria, VA: ASTD.

Kitzinger, J. (1995). Qualitative research: introducing focus groups. Bmj, 311(7000), 299 302. doi: 10.1136/bmj.311.7000.299

Ludwikowska, K. (2019). Teacher Competence Inventory: An Empirical Study on FutureOriented Competences of the Teaching Profession in Higher Education in India. Education \& Training, 61(9), 1123-1137.

Mackintosh, N. J. (1983). Conditioning and associative learning (p. 316). Oxford University Press.

Nickols, F. W. (2005). Why a stakeholder approach to evaluating training. Advances in Developing Human Resources, 7(1), 121-134.

Phillips, J. J. (1997). A rational approach to evaluating training programs... including calculating ROI. Journal of Lending and Credit Risk Management, 79, 43-50.

Polak, R., Finkelstein, A., Paganoni, S., Welch, R., \& Silver, J. K. (2019). Cooking online with a Chef: Health Professionals' Evaluation of a Live Culinary Coaching 
Module. Nutrition and Metabolic Insights, 12.https://doi.org/10.1177/1178638819887397

Purnell, M. (2020). Findings from a training needs analysis survey to support health professionals across the research lifecycle. Health Information \& Libraries Journal, 37(2), 118-127.

Rangel, A., Camerer, C., \& Montague, P. R. (2008). A framework for studying the neurobiology of value-based decision making. Nature Reviews Neuroscience, 9(7), 545-556.

Reigeluth, C., Beatty, B., \& Myers, R. (2017). Instructional-design theories and models: The learnercentered paradigm of education (Volume IV).

Rothwell, W. J., \& Kazanas, H. C. (2011). Mastering the instructional design process: $A$ systematic approach. John Wiley \& Sons.

Rapley, T. (2018). Doing conversation, discourse and document analysis (Vol. 7). Sage.

Salas, E., \& Stagl, K. C. (2009). Design training systematically and follow the science of training. In Locke, E. (Ed.), Handbook of principles of organizational behavior: Indispensible knowledge for evidence-based management, (pp.59-84). John Wiley \& Sons.

Sedek, M., Mahmud, R., Jalil, H. A., \& Daud, S. M. (2012). Types and levels of ubiquitous technology use among ICT undergraduates. Procedia-Social and Behavioral Sciences, 64, 255-264.

Subramani, M. R., \& Rajagopalan, B. (2003). Knowledge-sharing and influence in online social networks via viral marketing. Communications of the ACM, 46 (12): 300307.

Sutton, R. S., \& Barto, A. G. (1998). Reinforcement Learning: An Introduction (Vol. 135). MIT Press.

Strack, F., \& Deutsch, R. (2004). Reflective and impulsive determinants of social behavior. Personality and Social Psychology Review, 8(3), 220-247. https://journals.sagepub.com/doi/abs/10.1207/s15327957pspr0803_1

Watkins, R., \& Kaufman, R. (2002). Assessing and evaluating: Differentiating perspectives. Performance Improvement, 41(2), 22-28.

Zajonc, R. B. (1980). Feeling and thinking: Preferences need no inferences. American psychologist, 35(2), 151.

Fouad, N. (2017). Viral marketing effect on digital knowledge acquisition. Alexandria: The Journal of National and International Library and Information Issues, 27(1), 10. https://doi.org/10.1177\%2F0955749017718705

Zainudin, Z. N., \& Yusop, Y. M., (2018). Client's Satisfaction in Face-To-Face Counselling and Cyber Counseling Approaches: A Comparison. International Journal of Academic Research in Business and Social Sciences, 8(3), 677-684. https://doi.org/10.6007/IJARBSS/v8-i8/4462

Zainudin, Z. N., Yusop, Y. M., Hassan, S. A., Alias, B. S. (2019). The Effectiveness of Cybertherapy for the Introvert and Extrovert Personality Traits. Malaysian Journal of Medicine and Health Sciences, 15(Supp1), 105-109. 